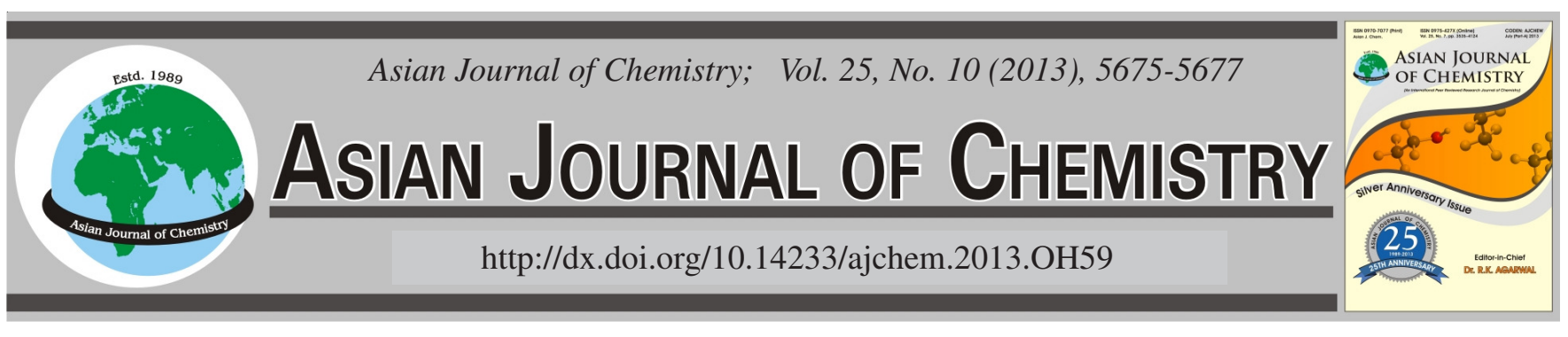

\title{
Drying Shrinkage and Gel/Space Ratio of Blended Cement Pastes with Fly Ash $\dagger$
}

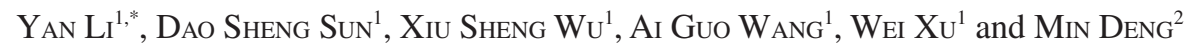

${ }^{1}$ School of Materials and Chemistry Engineering, Anhui University of Architecture, Hefei 230022, P.R. China

${ }^{2}$ College of Materials Science and Engineering, Nanjing University of Technology, Nanjing 210009, P.R. China

*Corresponding author: E-mail: lyc@ aiai.edu.cn

AJC-13302

\begin{abstract}
This paper reports the drying shrinkage and gel/space ratio of blended cement pastes with fly ash. In this study, Portland cement was used as the basic cementitious material. Fly ash was used as cement replacement material. The samples produced from fresh pastes were demoulded after a day; then they were cured at $20 \pm 1{ }^{\circ} \mathrm{C}$ with $50 \pm 3 \%$ relative humidity until the samples were used for measurement at different ages. The degree of cement hydration of the plain cement pastes was determined by determining the non-evaporable water content. The degree of fly ash reaction in blended cement paste with fly ash was determined using a selective dissolution procedure. The degree of cement hydration in blended cement paste with fly ash was estimated based on the relation between the degree of cement hydration and effective water to cementitious (w/c) ratio. The gel/space ratio of blended cement paste was evaluated based on the degrees of cement hydration and fly ash reaction. The results show that blended cement paste possesses lower the gel/space ratio and drying shrinkage value than that of plain cement paste and the determined gel/space ratio correlates linearly with the data on the drying shrinkage.
\end{abstract}

Key Words: Drying shrinkage, Gel/space ratio, Cement paste, Fly ash, Hydration.

\section{INTRODUCTION}

Fly ash, a by-product from coal power plants, has been widely used in blended cements ${ }^{1}$. As fly ash hydrates, empty space is filled by the hydration product, the pore structure will change, resulting in a change of gel/space ratio, which is defined as the ratio of the volumes of the hydrated cement to the sum of the volumes of the hydrated cement and of the capillary pore $^{2}$. Therefore, the gel/space ratio and the drying shrinkage should be naturally closely linked. It is necessary to research the relationship between the drying shrinkage and gel/space ratio. However, little work has been done on the relationship between the drying shrinkage and gel/space ratio. Therefore, this paper carried out the above research.

\section{EXPERIMENTAL}

Type P.I. 52.5R Portland cement produced by Tongling Conch Cement Company Limited, Anhui, China was used. Type II fly ash from Hefei Jinyuan Thermal Power Plant was also used.

Sample preparation and drying shrinkage measurement: The mix proportions of the cement paste are given in Table-1. Portland cement was used as the basic cementitious material. Fly ash was added as a partial replacement of the cement at levels of $50 \%$ by weight of the total cementitious material. The water-to-cementitious material (Portland cement + fly ash) ratio (w/c) was 0.3 by weight.

\begin{tabular}{lcccc}
\multicolumn{5}{c}{ TABLE-1 } \\
MIX PROPORTIONS OF CEMENT PASTES \\
\cline { 1 - 2 } Sample & \multicolumn{2}{c}{ Mix proportion (wt \%) } & \multirow{2}{*}{ w/c } & \multirow{2}{*}{ SP (wt \%) } \\
\cline { 2 - 3 } & PC & FA & & \\
\hline 50FA & $50 \%$ & $50 \%$ & 0.30 & 0 \\
PC30 & $100 \%$ & $0 \%$ & 0.30 & 0 \\
PC26 & $100 \%$ & $0 \%$ & 0.26 & 0.10 \\
PC22 & $100 \%$ & $0 \%$ & 0.22 & 0.25 \\
PC19 & $100 \%$ & $0 \%$ & 0.19 & 0.40 \\
\hline
\end{tabular}

A rotary mixer was used for mixing. To increase the homogeneity, cementitious materials were first blended in the mixer for $5 \mathrm{~min}$ before mixing with water. After water was added, the mixture was then mixed at low speed for $2 \mathrm{~min}$ and left for $30 \mathrm{~s}$ and further mixed at high speed for another $2 \mathrm{~min}$. After that, the mixture was poured into oiled moulds $(20 \mathrm{~mm}$ $\times 20 \mathrm{~mm} \times 80 \mathrm{~mm}$ ), compacted and covered at $20{ }^{\circ} \mathrm{C}$ and $>$ $95 \%$ relative humidity $(\mathrm{RH})$. After $24 \mathrm{~h}$, the mixture was unmolded and prepared for drying shrinkage measurements, the initial readings of length $\left(l_{0}\right)$ were recorded. After that, the specimens were exposed to drying in a humidity cabinet at

$†$ Presented to the 6th China-Korea International Conference on Multi-functional Materials and Application, 22-24 November 2012, Daejeon, Korea 
$20 \pm 1^{\circ} \mathrm{C}$ and $50 \pm 3 \% \mathrm{RH}$ controlled by $\mathrm{Mg}\left(\mathrm{NO}_{3}\right)_{2}$ saturated salt solutions until testing and the length change was measured periodically. Drying shrinkage length measurements were carried out using four specimens for each measurement up to the age of 28 days and average values were reported.

Drying shrinkage rate was calculated by using the following formula:

$$
\mathrm{L}_{\mathrm{t}}=\left(l_{0}-l_{\mathrm{t}}\right) \times 100 / 80
$$

where $l_{0}$ is initial reading of length, $l_{\mathrm{t}}$ is reading of length at various ages, $\mathrm{L}_{\mathrm{t}}$ is drying shrinkage rate at various ages.

Determination of non-evaporable water $\left(\mathbf{W}_{\mathbf{n}}\right)$ : The loss on ignition method (LOI) was used to determine the nonevaporable water contents at all selected ages of hydration. Small pieces from the plain and blended cement pastes were pulverized and immersed in ethanol to stop further hydration. To determine the $\mathrm{W}_{\mathrm{n}}$ content, $1 \mathrm{~g}$ of the pulverized samples were heated in an oven at $105^{\circ} \mathrm{C}$ for $24 \mathrm{~h}$ and then in a muffle furnace at $950{ }^{\circ} \mathrm{C}$ for $3 \mathrm{~h}$. The non-evaporable water content was obtained as the difference in mass between the sample heated at $105{ }^{\circ} \mathrm{C}$ and $950{ }^{\circ} \mathrm{C}$ normalized by the mass after heating to $950{ }^{\circ} \mathrm{C}$ and correcting for the loss on ignition of unhydrated cement.

Determination of reaction degree of fly ash: In the present work, the reaction degree of fly ash was determined by a selective dissolution method. In this study, an $\mathrm{HCl}$ and $\mathrm{Na}_{2} \mathrm{CO}_{3}$ solution were selected for the dissolving solution. The procedure for this method is as described in the literature ${ }^{3}$.

\section{RESULTS AND DISCUSSION}

Reaction degree: The reaction degree of the fly ash in blended cement paste was determined by a selective dissolution method. The degrees of cement hydration in the the plain cement paste were determined according to eqn. (2).

$$
\alpha_{\mathrm{c}}=100 \times \mathrm{W}_{\mathrm{n}} / 0.23
$$

where $\alpha_{c}$ is the degree of cement hydration in the plain cement pastes, $\mathrm{W}_{\mathrm{n}}$ is the non-evaporable water content of the plain cement pastes.

The degree of cement hydration in plain cement pastes and the degree of fly ash in blended cement paste are shown in Table-2.

\section{TABLE-2}

HYDRATION DEGREE OF THE CEMENT IN PLAIN CEMENT PASTES AND THE FLY ASH IN 50 FA PASTES

\begin{tabular}{ccccccccc}
\hline \multirow{2}{*}{ Sample } & \multicolumn{2}{c}{$\begin{array}{c}\text { Mix Proportion } \\
(\text { wt } \%)\end{array}$} & & \multicolumn{4}{c}{ Degree of reaction $(\%)$} \\
\cline { 2 - 3 } \cline { 7 - 9 } & PC $(\%)$ & FA $(\%)$ & & 3 days & 7 days & 14 days & 28 days \\
\hline 50FA & 50 & 50 & 0.30 & 2.58 & 2.99 & 4.15 & 4.46 \\
PC30 & 100 & 0 & 0.30 & 42.65 & 43.48 & 45.74 & 46.87 \\
PC26 & 100 & 0 & 0.26 & 35.47 & 37.55 & 40.26 & 44.24 \\
PC22 & 100 & 0 & 0.22 & 32.62 & 34.65 & 35.31 & 37.61 \\
PC19 & 100 & 0 & 0.19 & 28.01 & 31.04 & 33.20 & 35.86 \\
\hline
\end{tabular}

According to literature ${ }^{2}$, the degree of hydration of cement strongly depends on the $\mathrm{w} / \mathrm{c}$ ratio, an equation describing the relationship between the degree of cement hydration and the w/c ratio can be written $\mathrm{as}^{2}$ :

$$
\alpha_{\mathrm{c}}=\mathrm{ae}^{(-\mathrm{b} / \mathrm{W} / \mathrm{C})}
$$

where $\alpha_{c}$ is the degree of hydration of cement in the plain cement pastes, w/c is the water-to-cement ratio and $\mathrm{a}$ and $\mathrm{b}$ are empirical constants. Using regression analysis, the constants $\mathrm{a}$ and $\mathrm{b}$ and the correlation coefficients $\left(\mathrm{r}^{2}\right)$ of the fitting can be obtained (Table-3). From Table-3, it can be seen that the experimental data have a good correlation.

TABLE-3

REGRESSION ANALYSIS OF THE DEGREE OF HYDRATION OF CEMENT IN PLAIN CEMENT PASTES

\begin{tabular}{ccccc}
\hline Regression & \multirow{2}{*}{$\begin{array}{c}\text { Curing age } \\
\text { equation }\end{array}$} & \multicolumn{2}{c}{ Constants } & Correlation \\
\cline { 3 - 4 } (days) $\mathrm{r}^{2}$ & $\mathrm{a}$ & $\mathrm{b}$ & \\
& 3 & 71.11 & 0.1757 & 0.9869 \\
& 7 & 73.67 & 0.1660 & 0.9666 \\
$\alpha_{\mathrm{c}}=\mathrm{ae}^{(-\mathrm{b} / \mathrm{w} / \mathrm{C})}$ & 7 & 77.63 & 0.1662 & 0.9572 \\
& 14 & 76.83 & 0.1485 & 0.9531 \\
\hline
\end{tabular}

As fly ash is partially reactive, the reactive part of fly ash should be taken into account in the effective w/c ratio of blended cement paste with fly ash. Thus, according to literature ${ }^{2}$, the degrees of hydration of the cement in blended cement paste can be calculated by eqn. 4 :

$$
\alpha_{c}=a e^{\left(-b / W /\left(C+a_{F} F\right)\right)}
$$

where $\mathrm{C}$ and $\mathrm{F}$ are the original fractions of cement and fly ash in blended cement paste based on ignited weight and ${ }_{\mathrm{F}}^{\mathrm{a}}$ is the the degree of fly ash reaction at different ages. Thus, the degrees of hydration of the cement in blended cement paste with fly ash can be calculated (Table-4). Comparing to Table-

\begin{tabular}{|c|c|c|c|c|c|c|}
\hline \multicolumn{7}{|c|}{$\begin{array}{c}\text { TABLE-4 } \\
\text { DEGREE OF HYDRATION OF CEMENT } \\
\text { IN BLENDED CEMENT PASTE }\end{array}$} \\
\hline \multirow[t]{2}{*}{ Sample } & \multicolumn{2}{|c|}{$\begin{array}{l}\text { Mix Proportion } \\
(\text { wt } \%)\end{array}$} & \multirow[t]{2}{*}{ w/c } & \multicolumn{3}{|c|}{$\begin{array}{c}\text { Degree of hydration of cement } \alpha_{c} \\
(\%)\end{array}$} \\
\hline & PC (\%) & FA $(\%)$ & & 3 days 7 days & 14 days & 28 days \\
\hline $50 \mathrm{FA}$ & 50 & 50 & 0.3 & $\begin{array}{ll}50.72 & 53.53 \\
\end{array}$ & 56.39 & 57.74 \\
\hline
\end{tabular}
2 , it can be seen that the degree of cement hydration in blended cement paste is higher than that of the plain Portland cement pastes.

Gel/space ratios of plain cement paste and blended cement paste: Gel/space ratio is defined as the ratio of the volume occupied by hydrated cement to the sum of the volumes occupied by hydrated cement and by capillary pores that are present in the matrix. According to literature ${ }^{4}$, the gel/ space ratio of plain cement paste can be calculated according to the following equation:

$$
\mathrm{X}_{\mathrm{PC}}=2.06 \gamma_{\mathrm{c}} \alpha_{\mathrm{c}} /\left(\gamma_{\mathrm{c}} \alpha_{\mathrm{c}}+\mathrm{w} / \mathrm{c}\right)
$$

where $\mathrm{X}_{\mathrm{PC}}$ is the gel/space ratio of the plain cement paste, $\gamma_{\mathrm{c}}$ is the specific volume of anhydrous cement, $\alpha_{c}$ is the degree of hydration of cement and w/c is the original water-to-cement ratio. In this study, the cement used had the density of $3.13 \mathrm{~g} / \mathrm{cm}^{3}$, corresponding to $\gamma_{c}=1 / 3.13=0.32$.

The application of the above equation in case of the paste prepared with blended cements is debatable as implied by the conflicting works published on the issue. According to literature $^{4}$, for cement pastes containing fly ash, the gel/space ratio is modified to:

$$
\mathrm{X}_{\mathrm{FA}}=\left(2.06 \gamma_{c} \alpha_{c} \mathrm{C}+2.41 \gamma_{\mathrm{F}} \alpha_{\mathrm{F}} \mathrm{F}\right) /\left(\gamma_{c} \alpha_{c} \mathrm{C}+1 \gamma_{\mathrm{F}} \alpha_{\mathrm{F}} \mathrm{F}+\mathrm{W}\right)
$$


where $\mathrm{X}_{\mathrm{FA}}$ is the gel/space ratio of blended cement paste with fly ash; $\gamma_{\mathrm{c}}$ and $\gamma_{\mathrm{F}}$ are the specific volumes and $\alpha_{\mathrm{c}}$ and $\alpha_{\mathrm{F}}$ are the degrees of reaction of cement and fly ash, respectively; $\mathrm{C}$ and $\mathrm{F}$ are the original fractions of cement and fly ash in the blended cement paste on an ignited basis; and $\mathrm{W}$ is the weight of water mixed with per gram of ignited blended cement paste.

According eqns. (5) and (6), the gel/space ratios of the plain cement paste and the blended cement paste can be calculated, the results are shown in Table-5. It can be seen that the gel/space ratios of the blended cement paste with fly ash is lower than that of plain cement paste at the same ages.

\begin{tabular}{cccccc}
\multicolumn{5}{c}{ TABLE-5 } \\
\multicolumn{5}{c}{ CALCULATED GEL/SPACE RATIOS OF PLAIN } \\
CEMENT AND BLENDED CEMENT PASTES \\
\cline { 3 - 6 } w/c & Fly ash & \multicolumn{4}{c}{ Gel/space ratios } \\
\hline 0.30 & replacement (wt $\%)$ & 3 days & 7 days & 14 days & 28 days \\
\hline 0.30 & 0 & 0.4673 & 04900 & 0.5202 & 0.5317 \\
& 0 & 0.6149 & 0.6560 & 0.6755 & 0.6866 \\
\hline
\end{tabular}

Drying shrinkage: Drying shrinkage results are shown in Fig. 1. It was clearly observed in Fig. 1 that blended cement pastes with fly ash (50FA) had lower drying shrinkage rate than that of the plain cement pastes (PC30). The experimental results indicate that fly ash changes the drying shrinkage of blended cement paste very significantly.

Relationship between gel/space ratio and drying shrinkage: Fig. 2 shows the relationship between gel/space ratio and drying shrinkage of blended cement pastes with fly ash. It is observed that the gel/space ratio of blended cement paste with fly ash is almost a linear function of the drying shrinkage. The value of the correlation coefficient square $\left(\mathrm{r}^{2}\right)$ from the regression analysis is 0.9637 .

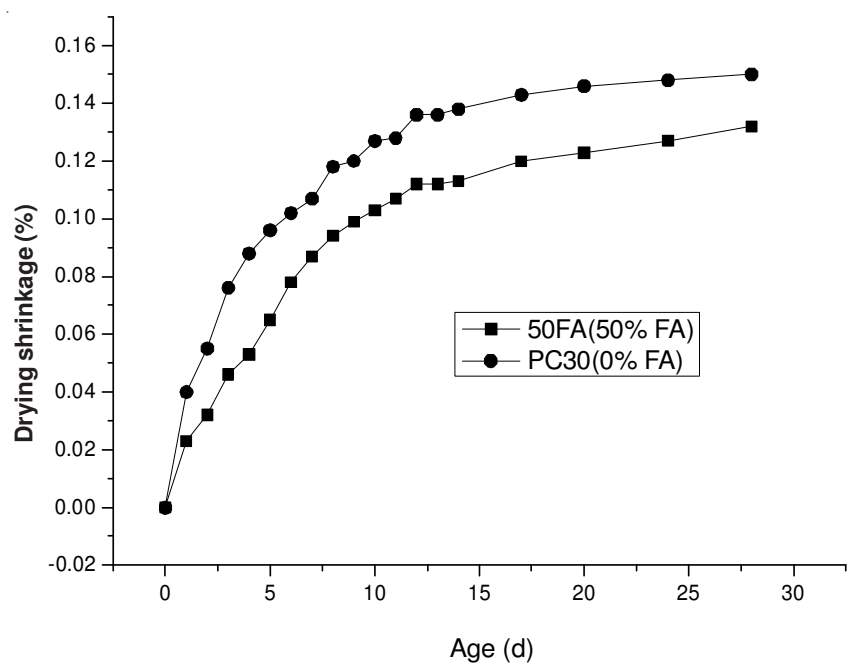

Fig. 1. Curves on dry shrinkage rate of cement pastes

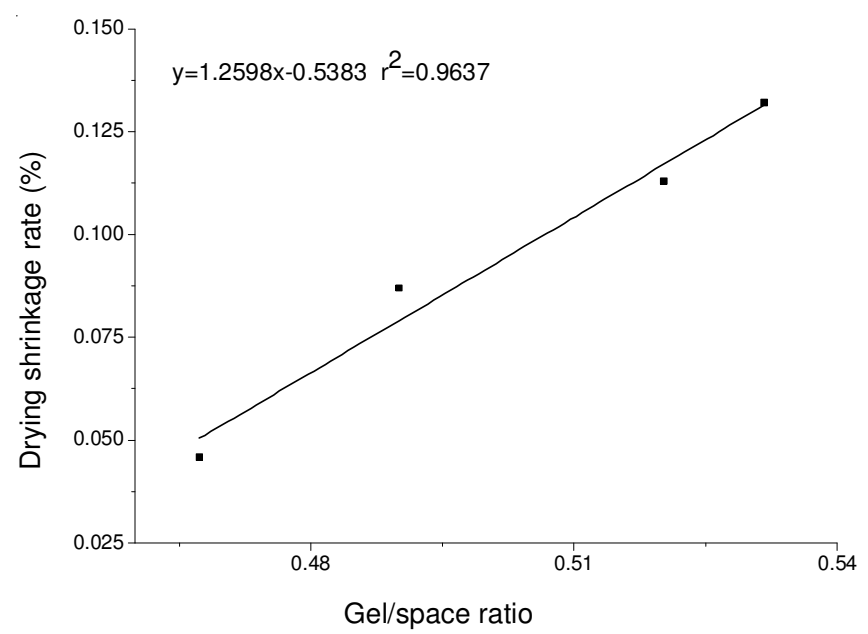

Fig. 2. Relationship between gel/space ratio and drying shrinkage of blended cement paste

\section{Conclusion}

From the laboratory investigation the following conclusions were made: (1) The drying shrinkage rates of the blended cement paste with fly ash is lower than that of plain cement paste. (2) The determined gel/space ratio of the blended cement paste with fly ash is lower than that of plain cement paste. (3) A linear relationship is established between gel/space ratio and drying shrinkage rate of the blended cement paste with fly ash.

\section{ACKNOWLEDGEMENTS}

This work was financially supported by National Key Basic Research Development Program (973 Program) sub-project (2009CB623105).

\section{REFERENCES}

1. T. Nochaiya and W. Wongkeo, Fuel, 89, 768 (2010).

2. L. Lam, Y.L. Wong and C.S. Poon, Cement Concrete Res., 30, 747 (2000).

3. P. Termkhajornkit, T. Nawa and K. Kurumisawa, Cement Concrete Comp., 28, 781 (2006).

4. S. Antiohos, A. Papageorgiou and S. Tsimas, Cement Concrete Res., 36, 2123 (2006). 